\title{
Improving uptake of flexible sigmoidoscopy screening: a randomized trial of nonparticipant reminders in the English Screening Programme
}

\section{(c) (1)}

\section{Authors}

Robert S. Kerrison ${ }^{1}$, Lesley M. McGregor ${ }^{1}$, Sarah Marshall ${ }^{2}$, John Isitt $^{3}$, Nicholas Counsell ${ }^{4}$, Colin J. Rees ${ }^{5}$, Christian von Wagner ${ }^{1}$

\section{Institutions}

1 Health Behaviour Research Centre, Department of Epidemiology and Public Health, University College London, London, United Kingdom

2 St Mark's Bowel Cancer Screening Centre, St Mark's Hospital, Harrow, United Kingdom

3 Resonant Behaviour Change and Social Marketing, London, United Kingdom

4 Cancer Research UK and University College London Cancer Trials Centre, University College London, London, United Kingdom

5 South Tyneside NHS Foundation Trust, South Tyneside School of Medicine, Pharmacy and Health, Durham University, Durham, United Kingdom

submitted 4.5.2016

accepted after revision 29.8.2016

\section{Bibliography}

DOI http://dx.doi.org/10.1055/s-0042-118452

Published online: 20.12.2016 | Endoscopy 2017; 49: 35-43

(c) Georg Thieme Verlag KG Stuttgart · New York

ISSN 0013-726X

\section{Corresponding author}

Christian von Wagner, PhD, Health Behaviour Research Centre, Department of Epidemiology and Public Health, University College London, 1-19 Torrington Place, London WC1E 7HB, United Kingdom,

Fax: +44-207-6798354,

robert.kerrison.13@ucl.ac.uk

Appendix e1 - e4

Online content viewable at: https://www.thieme-connect.com/ DOI/DOI?10.1055/s-0042-118452

Scan this QR-Code to watch the video comment.

\section{ABSTRACT}

Background and study aims Uptake of flexible sigmoidoscopy screening in the English Bowel Scope Screening (BSS) Programme is low. The aim of this study was to test the impact of a nonparticipant reminder and theory-based leaflet to promote uptake among former nonresponders (previously did not confirm their appointment) and nonattenders (previously confirmed their appointment but did not attend).

Patients and methods Eligible adults were men and women in London who had not attended a BSS appointment within 12 months of their invitation. Individuals were randomized (1:1:1) to receive no reminder (control), a 12-month reminder plus standard information booklet (TMR-SIB), or a 12-month reminder plus bespoke theorybased leaflet (TMR-TBL) designed to address barriers to screening. The primary outcome of the study was the proportion of individuals screened within each group 12 weeks after the delivery of the reminder.

Results A total of 1383 men and women were randomized and analyzed as allocated ( $n=461$ per trial arm). Uptake was $0.2 \%(n=1)$, $10.4 \%(n=48)$, and $15.2 \%(n=70)$ in the control, TMR-SIB, and TMRTBL groups, respectively. Individuals in the TMR-SIB and TMR-TBL groups were significantly more likely to attend screening than individuals in the control group (adjusted odds ratio [OR] 53.7, $95 \%$ confidence interval $[\mathrm{Cl}] 7.4-391.4, P<0.001$ and $\mathrm{OR} 89.0,95 \% \mathrm{Cls}$ 12.3-645.4, $P<0.01$, respectively). Individuals in the TMR-TBL group were also significantly more likely to attend screening than individuals in the TMR-SIB group (OR 1.7, 95\%Cls 1.1-2.5, $P=$ $0.01)$. Across all groups, former nonattenders were more likely to participate in screening than former nonresponders (uptake was $14.2 \%$ and $8.0 \%$, respectively; OR $2.5,95 \% \mathrm{Cls} 1.4-4.4, P<0.01$ ). The adenoma detection rate among screened adults was $7.6 \%$, which is comparable to the rate in initial attenders.

Conclusions Reminders targeting former nonparticipants can improve uptake and are effective for both former nonresponders and nonattenders. Theory-based information designed to target barriers to screening added significantly to this strategy. 


\section{Introduction}

In March 2013, NHS England extended its national Bowel Cancer Screening Programme to include once-only flexible sigmoidoscopy screening for men and women aged 55 years [1]. The decision to extend the program and include flexible sigmoidoscopy was made in response to the results of a large UK randomized controlled trial (RCT), which demonstrated that a one-off screen between the ages of 55 and 64 years significantly reduced the incidence and mortality of colorectal cancer (CRC) among screened adults [2].

Uptake of the test (also referred to as bowel scope screening [BSS]) in England is currently very low (only $43 \%$ of invitees attend an appointment) [3], which will ultimately undermine the clinical effectiveness of the program [4]. Data on uptake in other countries are sparse, but it has been documented to be as low as $29 \%$ in regions of Italy [5] and as high as $63 \%$ in the Norwegian Colorectal Cancer Prevention Trial [6].

Detailed surveys issued to nonparticipants and their healthcare providers have identified the most prevalent patient-related factors for not attending a flexible sigmoidoscopy appointment as: a lack of current health problems, practical barriers (i.e. inconvenient appointment time/day), worry about pain, discomfort, or injury associated with the examination, and not wanting to know about any health issues [7-9]. Subsequent studies have suggested that interventions which address patient-specific barriers to the test might improve uptake [10, $11]$; however, the evidence to support the use of such strategies is inconsistent [12-18].

Organizational changes, such as those affecting the mechanisms for scheduling appointments, self-referral, and patient outreach have been more effective at increasing patient participation [19-23]. Pre-notification letters, timed appointments, and pre-appointment reminders have all been shown to improve uptake of flexible sigmoidoscopy screening and, as with other screening, these specific strategies have been incorporated into the BSS pathway [5,24-26]. Repeat invitations have additionally been shown to improve uptake of CRC screening tests (such as the fecal occult blood test and colonoscopy) by providing additional opportunities for people to take part [27-29]. In Italy, Senore et al. made similar observations in the context of a flexible sigmoidoscopy-based program when they sent former nonresponders a reminder letter 3 months after the invitation, yielding a $4.5 \%$ absolute increase in uptake [5].

In the BSS program, invitees who do not attend screening at the age of 55 years can self-refer for the test up until the age of 60 , but do not receive a formal reminder of this opportunity. A recent single-arm feasibility study examining the format of a 12-month reminder for a center in London found that, when sent with a bespoke cover letter and information leaflet, the reminder facilitated uptake in $15.5 \%$ of former nonresponders [30]. Although highly promising, these current studies of nonresponder reminders are limited to observational data from single-arm trials $[5,30]$. The effectiveness of these interventions and some of their key components therefore still require formal evaluation in multi-arm RCTs. One such component requiring further investigation is the bespoke, theory-based leaflet used in the feasibility study [30], which had been designed to address several barriers to screening by providing bespoke information on how to get to the screening center and by including testimonials from locally screened adults [30]. Using local tailoring for the whole program would incur additional financial and logistical costs, which would need to be justified.

Another hitherto untested component of these reminders is their differential impact on specific groups of nonparticipants, as to date current studies have focused exclusively on former nonresponders (i.e. individuals who previously did not confirm nor attend their appointment) [5,30]. Previous research has shown that individuals who confirm an appointment, but then do not attend (i.e. former nonattenders), are both demographically and qualitatively different from their screened and nonresponding counterparts [31], with previously screened adults having "better subjective health" and "lower levels of deprivation" and former nonresponders having "lower levels of perceived benefits and anticipated regret" and higher levels of "cancer fear and fatalism" [31]. As it stands, there is no published information about the prevalence of this important subgroup of nonparticipants in the English BSS program or how they would respond to interventions inviting them to re-engage with the program.

The present study therefore set out to extend the evaluation of nonparticipant reminders to increase uptake of flexible sigmoidoscopy screening by: 1) comparing uptake between individuals receiving a reminder compared with usual care (i. e. no reminder) in an RCT; 2) subdividing nonparticipants into former nonattenders and former nonresponders; and 3) testing the added benefit of including a bespoke theory-based leaflet with the reminder.

\section{Patients and methods}

\section{Study design and trial setting}

We performed a single-blind RCT with three parallel arms in the London Boroughs of Brent and Harrow. Researchers were blinded to the treatment that subjects received until all data had been collected at the end of the study. Because individuals were given a reminder plus the standard information booklet, no reminder, or a reminder plus the locally tailored theorybased leaflet, it was not possible to blind them to the treatment they received. In terms of the study setting, the London Boroughs of Brent and Harrow have below-average uptake (40\% vs. $43 \%$, respectively), and individuals living in these boroughs predominantly live in the most ethnically diverse and socioeconomically deprived areas of England [4].

\section{Study population}

Eligible adults were men and women registered with a general practice in the London Boroughs of Brent and Harrow. Adults registered with these practices were eligible for inclusion in the study if they had not attended a BSS appointment within 12 months of receiving their invitation. Eligible adults included both those who previously did not respond to the initial invitation at the age of 55 years (former nonresponders) as well as 


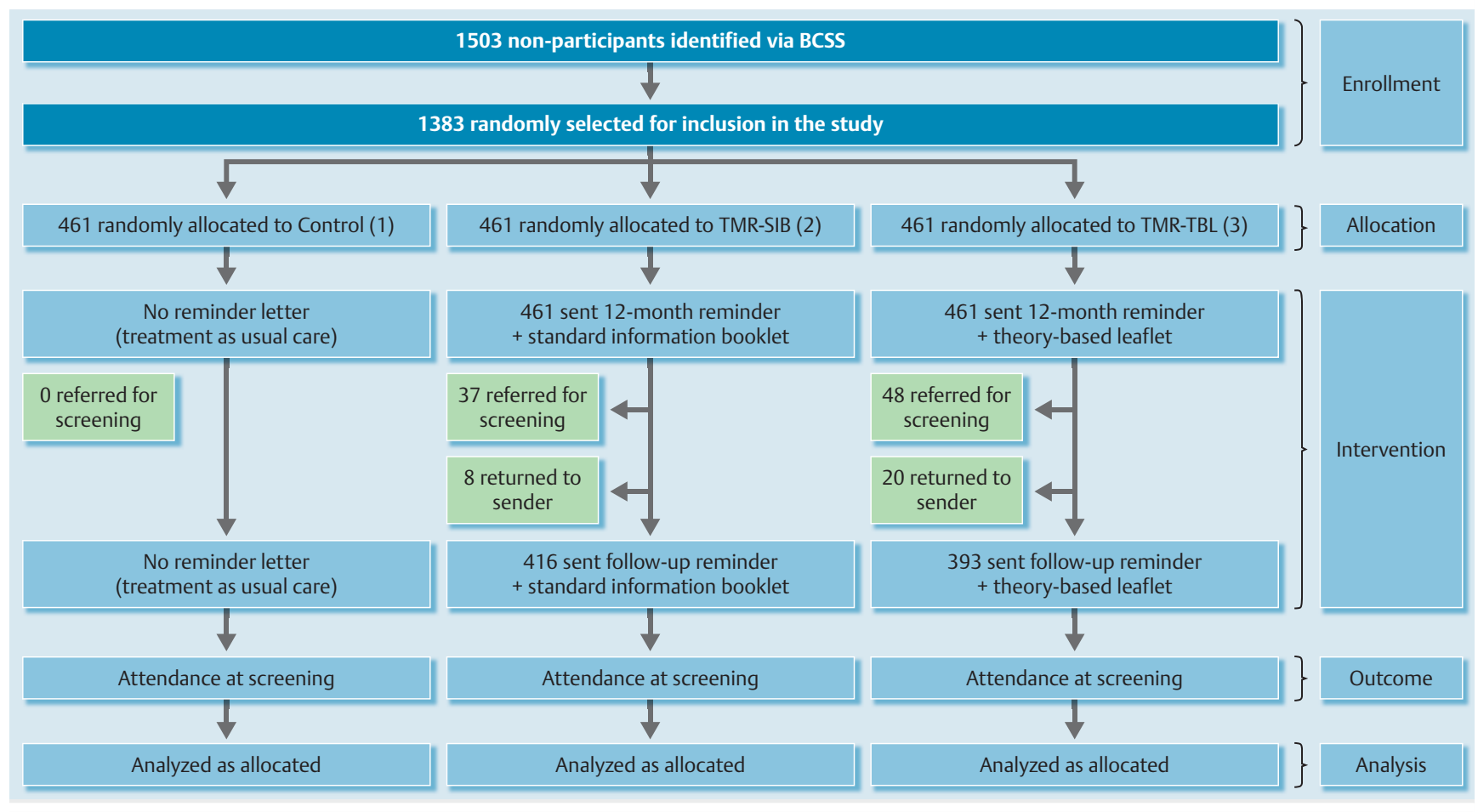

- Fig. 1 Trial flowchart/CONSORT diagram. BCSS, Bowel Cancer Screening System; TMR, 12-month reminder; SIB, standard information booklet; TBL, theory-based leaflet.

those who confirmed an appointment but did not attend (former nonattenders).

\section{Procedures}

Eligible adults were identified from the NHS Bowel Cancer Screening System (BCSS) [32]. To ensure workforce capacity (i.e. that all self-referred appointments could be facilitated without disruption to routine appointments), eligible adults were enrolled over a 20-week period spanning February to August 2015. On the basis that there was capacity to facilitate an additional five appointments per week, and that $5 \%$ of individuals across the three groups would make and attend an appointment each week, we conservatively selected 69 adults for inclusion in the study each week (from a variable weekly total) using simple pseudo-random selection methods [33] ( $\boldsymbol{\text { Fig. }}$ 1). Individuals selected for inclusion in the study were then randomly assigned using simple pseudorandom allocation methods (in a 1:1:1 ratio) to receive: no reminder (control); a mailed 12-month reminder plus a standard information booklet (TMR$\mathrm{SIB}$ ); or a mailed 12-month reminder plus a locally tailored theory-based leaflet (TMR-TBL) designed to address barriers to screening.

Individuals allocated to the control group were provided with usual care and therefore did not receive a reminder. Individuals allocated to the reminder groups were sent a reminder letter with one of two leaflets, an appointment-request slip, and a freepost return envelope addressed to St Mark's Bowel Cancer Screening Centre ( $\triangleright$ Fig. 1 ).

Individuals in both reminder groups were able to book an appointment by returning their appointment-request slip in the freepost envelope provided, thereby initiating a call from a member of the administrative team to arrange an appointment, or by calling the screening center directly on the Freephone telephone number highlighted in the reminder letter.

Individuals not responding to the reminder within 4 weeks were sent a follow-up reminder ( $\bullet$ Fig. 1 ), which also included an appointment-request slip, the allocated information leaflet, and a freepost return envelope. Individuals were then given 8 more weeks to respond, after which they were not included in the study results. Individuals who self-referred for the test also received a pre-appointment text-message reminder and telephone call, as per routine appointments at St Mark's Hospital.

The study was approved by the North East-Tyne \& Wear South Research Ethics Service (Ref: 15/NE/0043) and was registered with the International Standard Randomised Controlled Trials Number Registry for transparency (trial ID: ISRCTN44293755).

\section{Intervention details}

Full descriptions of the intervention materials and their development are available in the feasibility study [30].

\section{2-month reminder}

The 12-month reminder was a personally addressed letter from St Mark's Hospital that invited recipients to make a new appointment by returning an appointment-request slip or by calling the Freephone telephone number for the screening center ( $\triangleright$ Appendix e1, available online). The reminder also gave recipients the option to express a preference for the day and time 
of the appointment, as well as the sex of the practitioner performing the test.

\section{Theory-based leaflet (TMR-TBL)}

The theory-based leaflet was a locally tailored leaflet co-designed by Resonant, a social marketing company specializing in health behavior (see - Appendix e2, available online). The development of the leaflet was based on two psychological models of behavior previously used to explain factors associated with uptake [34]: the Health Belief Model [35] and Social Cognitive Theory [36]. To address barriers to participation, the leaflet included an educational/knowledge-building component and several practical components designed to improve self-efficacy (including local transport information and directions to the hospital).

\section{Standard information booklet}

The standard information booklet was the same 16-page booklet that was previously sent with the initial invitation as part of the national program (available from: https://www.gov.uk/government/uploads/system/uploads/attachment_data/file/

423928 /bowel-scope-screening.pdf). The standard information booklet was developed by King's Health Partners who developed the booklet in accordance with principles put forth by NHS England's informed choice initiative [37].

\section{Follow-up reminder}

The follow-up reminder was a personally addressed letter from St Mark's Hospital that reiterated the opportunity to self-refer for screening up until the age of 60 years ( $\triangleright$ Appendix e3, available online).

\section{Measures}

Routinely available data on the BCSS were used to verify self-referral and attendance 4 and 12 weeks following the distribution of the 12-month reminder letter. The BCSS was also consulted to obtain the sex, area (i.e. Brent or Harrow), and initial episode status (i.e. former nonresponder or former nonattender) of each person included in the trial. For those who attended an appointment, the BCSS was additionally consulted to obtain the proportion of people screened who had one or more adenomas detected.

An area-based socioeconomic deprivation score was generated for each person by converting individual postcodes into a score on the 2010 Index of Multiple Deprivation (IMD) [38]. Area-level IMD scores were then categorized into tertiles of their regional distributions to enable comparisons between the most and least deprived areas.

\section{Statistics}

\section{Sample size}

The sample size ( $n=1383$ ) was calculated using a standard test of difference between two proportions. As the study included three trial arms (one receiving usual care and two receiving a reminder with one of two leaflets), the calculation was repeated for each pairwise comparison comprising a primary research question in the planned analysis. The final calculation gave a total sample size requirement of 461 people per trial arm to test for a $5 \%$ difference in uptake between any two of the three groups, with expected values of $0 \%, 5 \%$, and $10 \%$ for the control, TMR-SIB, and TMR-TBL groups respectively. The study was designed to detect differences at the two-sided $5 \%$ alpha level with a $20 \%$ margin for type II error.

\section{Data analysis}

Univariate logistic regression was used to investigate the associations between treatment groups and self-referral and uptake. To counteract the problem of multiple comparisons, we used the Bonferroni correction method, comparing outcomes to an adjusted significance level of 0.015. Adjusted odds ratios (ORs) and $95 \%$ confidence intervals (Cls) were calculated using multivariate logistic regression after adjusting for baseline characteristics. To explore possible associations between not attending a confirmed appointment and previous episode status (i.e. former nonattender, former nonresponder), we carried out a subgroup analysis using univariate and multivariate logistic regression.

The adenoma detection rate (ADR) was reported using descriptive statistics; the data were analyzed on an intention-totreat basis using SPSS software (version 22; IBM Corp., Armonk, New York, USA).

\section{Results}

\section{Sample characteristics}

The study took place between February and August 2015, with follow-up until October 2015. A total of 1383 adults were randomized and analyzed as allocated. The majority of individuals were registered with a general practice in the London Borough of Brent ( $n=928 ; 67.1 \%)$, did not respond to the initial invitation $(n=1255,90.7 \%)$, and were female $(n=727 ; 52.6 \%)$ ( $\vee$ Table 1).

\section{Uptake of bowel scope screening}

In total, 119 people (8.6\%) attended an appointment across all three study groups ( $\triangleright$ Table 2 ). A further 41 (3.0\%) made an appointment, but then either did not attend $(n=21)$ or cancelled $(n=20)$, leaving $1223(88.4 \%)$ adult men and women who neither made nor attended an appointment ( $\triangleright$ Table 2 ).

There was strong evidence of differences in booked and attended appointments between the reminder groups and the control ( $>$ Table 2 ). A total of 48 individuals $(10.4 \%$ ) in the TMR-SIB group and 70 (15.2\%) in the TMR-TBL group attended an appointment ( $\triangleright$ Table 2 ) compared with only $1(0.2 \%)$ in the control group (OR 53.5, $95 \% \mathrm{Cls} 7.4-389.1, P<0.001$; OR 82.4, $95 \% \mathrm{Cls} 11.4-595.6, P<0.001$ for the TMR-SIB and TMR-TBL groups, respectively). There was also a strong trend toward differences in uptake between the reminder groups, with individuals in the TMR-TBL group being more likely to attend an appointment than individuals in the TMR-SIB group (OR 1.5, $95 \%$ Cl $1.0-2.3, P=0.03)$.

Results were similar after adjusting for baseline characteristics in the multivariate analysis ( 
- Table 1 Description of the trial population.

\begin{tabular}{|c|c|c|c|c|}
\hline & $\begin{array}{l}\text { Control } \\
(n=461)\end{array}$ & $\begin{array}{l}\text { TMR-SIB } \\
(n=461)\end{array}$ & $\begin{array}{l}\text { TMR-TBL } \\
(n=461)\end{array}$ & $\begin{array}{l}\text { Total } \\
(n=1383)\end{array}$ \\
\hline \multicolumn{5}{|l|}{ Sex, $\mathrm{n}(\%)$} \\
\hline Female & $261(56.6)$ & $238(51.6)$ & $228(49.5)$ & $727(52.6)$ \\
\hline Male & $200(43.4)$ & $223(48.4)$ & $233(50.5)$ & $656(47.4)$ \\
\hline \multicolumn{5}{|l|}{ Area, n (\%) } \\
\hline Brent & $304(65.9)$ & $302(65.5)$ & $322(69.8)$ & $928(67.1)$ \\
\hline Harrow & $157(34.1)$ & $159(34.5)$ & $139(30.2)$ & $455(32.9)$ \\
\hline \multicolumn{5}{|c|}{ Tertile of deprivation (IMD score), n (\%) } \\
\hline Tertile $1(0.00-17.68)$ & $152(33.0)$ & $144(31.2)$ & $133(28.9)$ & $429(31.0)$ \\
\hline Tertile $2(17.69-27.50)$ & $164(35.5)$ & $162(35.0)$ & $179(38.8)$ & $505(36.5)$ \\
\hline Tertile $3(27.51-80)$ & $140(30.4)$ & $151(32.8)$ & $144(31.2)$ & $435(31.5)$ \\
\hline Missing & $5(1.1)$ & $4(0.9)$ & $5(1.1)$ & $14(1.0)$ \\
\hline \multicolumn{5}{|l|}{ Initial episode status, n (\%) } \\
\hline Nonresponder & $411(89.2)$ & $408(88.5)$ & $436(94.6)$ & $1255(90.7)$ \\
\hline Nonattender & $50(10.8)$ & $53(11.5)$ & $25(6.4)$ & $128(9.3)$ \\
\hline
\end{tabular}

- Table 2 Self-referral and uptake by trial arm (univariate and multivariate regression outcomes).

\begin{tabular}{|c|c|c|c|}
\hline & Mean, n (\%) & Unadjusted OR (95\%Cl) & Adjusted OR $(95 \% \mathrm{Cl})^{1}$ \\
\hline \multicolumn{4}{|c|}{ Made an appointment $(n=160)$} \\
\hline Control vs. TMR-SIB & 1 vs. 64 (0.2 vs. 13.9 ) & $74.16(10.24-536.97)^{2}$ & $73.27(10.11-531.11)^{2}$ \\
\hline Control vs. TMR-TBL & 1 vs. 95 (0.2 vs. 20.6) & $119.40(16.57-860.49)^{2}$ & $130.36(18.05-941.54)^{2}$ \\
\hline TMR-SIB vs. TMR-TBL & 64 vs. 95 (13.9 vs. 20.6$)$ & $1.61(1.14-2.28)^{3}$ & $1.78(1.25-2.54)^{3}$ \\
\hline \multicolumn{4}{|c|}{ Attended an appointment $(n=119)$} \\
\hline Control vs. TMR-SIB & 1 vs. 48 (0.2 vs. 10.4$)$ & $53.46(7.35-389.05)^{2}$ & $53.73(7.38-391.39)^{2}$ \\
\hline Controlvs. TMR-TBL & 1 vs. 70 (0.2 vs. 15.2 ) & $82.35(11.39-595.58)^{2}$ & $89.01(12.28-645.40)^{2}$ \\
\hline TMR-SIB vs. TMR-TBL & 48 vs. 70 (10.4 vs. 15.2 ) & $1.54(1.04-2.28)^{4}$ & $1.69(1.13-2.52)^{3}$ \\
\hline \multicolumn{4}{|c|}{$\begin{array}{l}\text { OR, odds ratio; } \mathrm{Cl} \text {, confidence interval. } \mathrm{n}=461 \text { for all groups, respectively. } \\
{ }^{1} \text { Adjusted } \mathrm{ORs} \text { and } 95 \% \mathrm{Cl} \text { are adjusted for sex, area, deprivation, and initial episode status. } \\
{ }^{2} P \leq 0.001 \\
{ }^{3} P \leq 0.01 \\
4 P<0.05\end{array}$} \\
\hline
\end{tabular}

dence of significant differences between the reminder groups and control (TMR-SIB vs. control: OR 53.7, $95 \%$ Cls 7.4-391.4, $P<0.001$; TMR-TBL vs. control: OR 89.0, $95 \%$ Cls $12.3-645.4, P$ $<0.001)$. After adjusting for baseline characteristics, there was also strong evidence for a difference in participation between intervention groups, with individuals in the TMR-TBL group being more likely to book and attend an appointment than individuals in the TMR-SIB group (OR 1.7, 95\%Cls 1.1-2.5; $P=$ 0.01 ). There was also strong evidence of a difference in uptake by initial episode status after adjusting for study group and other baseline characteristics ( $>$ Table 3 ), with former nonat- tenders being nearly twice as likely to book and attend an appointment than former nonresponders $(14.2 \%$ and $8.0 \%$, respectively; OR $2.5,95 \% \mathrm{Cl} 1.4-4.4 ; P<0.01)$. There was no evidence of an association between screening uptake and sex, regional IMD tertile, or area (all $P$ values >0.05; $>$ Table 3 ).

\section{Confirmed appointments}

A total of 41 individuals booked an appointment but did not attend. Attendance of a confirmed appointment was higher among former nonattenders than former nonresponders $(81.8 \%$ vs. $73.0 \%$ ); however, the results of the regression revealed that 
- Table 3 Self-referral and uptake by baseline characteristics (univariate and multivariate regression outcomes).

\begin{tabular}{|c|c|c|c|c|c|c|}
\hline & $\begin{array}{l}\text { Made an ap- } \\
\text { pointment, } \\
\text { n (\%) }\end{array}$ & $\begin{array}{l}\text { Unadjusted } \\
\text { OR } \\
(95 \% \mathrm{Cl})\end{array}$ & $\begin{array}{l}\text { Adjusted OR } \\
(95 \% \mathrm{CI})^{1}\end{array}$ & $\begin{array}{l}\text { Attended an } \\
\text { appointment, } \\
\text { n (\%) }\end{array}$ & $\begin{array}{l}\text { Unadjusted } \\
\text { OR } \\
(95 \% \mathrm{Cl})\end{array}$ & $\begin{array}{l}\text { Adjusted OR } \\
(95 \% \mathrm{Cl})^{1}\end{array}$ \\
\hline \multicolumn{7}{|l|}{ Sex } \\
\hline Women $^{2}(n=727)$ & $83(11.4)$ & - & - & $57(7.8)$ & - & - \\
\hline Men $(n=656)$ & $77(11.7)$ & $\begin{array}{l}1.03 \\
(0.74-1.44)\end{array}$ & $\begin{array}{l}0.94 \\
(0.67-1.33)\end{array}$ & $62(9.5)$ & $\begin{array}{l}1.23 \\
(0.84-1.79)\end{array}$ & $\begin{array}{l}1.18 \\
(0.80-1.75)\end{array}$ \\
\hline \multicolumn{7}{|l|}{ Area } \\
\hline Brent $^{2}(n=926)$ & $101(10.9)$ & - & - & $75(8.1)$ & - & - \\
\hline Harrow $(n=457)$ & $59(12.9)$ & $\begin{array}{l}1.21 \\
(0.86-1.71)\end{array}$ & $\begin{array}{l}1.39 \\
(0.89-2.18)\end{array}$ & $44(9.6)$ & $\begin{array}{l}1.21 \\
(0.82-1.79)\end{array}$ & $\begin{array}{l}1.34 \\
(0.80-2.22)\end{array}$ \\
\hline \multicolumn{7}{|l|}{ Deprivation } \\
\hline Tertile $1^{2}(n=429)$ & $49(11.4)$ & - & - & $38(8.9)$ & - & - \\
\hline Tertile $2(n=505)$ & $59(11.7)$ & $\begin{array}{l}1.03 \\
(0.69-1.54)\end{array}$ & $\begin{array}{l}1.20 \\
(0.74-1.95)\end{array}$ & $41(8.1)$ & $\begin{array}{l}0.91 \\
(0.57-1.44)\end{array}$ & $\begin{array}{l}1.05 \\
(0.61-1.81)\end{array}$ \\
\hline Tertile $3(n=435)$ & $51(11.7)$ & $\begin{array}{l}1.03 \\
(0.68-1.56)\end{array}$ & $\begin{array}{l}1.29 \\
(0.76-2.21)\end{array}$ & $40(9.2)$ & $\begin{array}{l}1.04 \\
(0.65-1.66)\end{array}$ & $\begin{array}{l}1.28 \\
(0.71-2.33)\end{array}$ \\
\hline \multicolumn{7}{|l|}{ Initial episode status } \\
\hline Nonresponder $^{2}(n=1256)$ & $138(11.0)$ & - & - & $101(8.0)$ & - & - \\
\hline Nonattender $(n=127)$ & $22(17.3)$ & $\begin{array}{l}1.70^{4} \\
(1.04-2.78)\end{array}$ & $\begin{array}{l}2.24^{3} \\
(1.30-3.85)\end{array}$ & $18(14.2)$ & $\begin{array}{l}1.89^{4} \\
(1.10-3.24)\end{array}$ & $\begin{array}{l}2.45^{3} \\
(1.36-4.40)\end{array}$ \\
\hline \multicolumn{7}{|c|}{$\begin{array}{l}\text { OR, odds ratio; } \mathrm{Cl} \text {, confidence interval. } \\
{ }^{1} \text { Adjusted ORs and } 95 \% \mathrm{Cls} \text { are adjusted for trial arm and all other covariates in the table. } \\
2 \text { Reference category. } \\
3 P \leq 0.01 \\
{ }^{4} P \leq 0.05\end{array}$} \\
\hline
\end{tabular}

there was no significant difference between these two groups (OR 1.4, 95\%Cls 0.4-4.6) (- Appendix e4). A significant difference in attendance was observed between men and women ( $80.5 \%$ vs. $68.3 \%$ ), with men being more likely to attend than their female counterparts (OR 2.2, $95 \% \mathrm{Cl} 1.0-4.7$ ). There were no significant differences in the nonattendance rate for any of the other covariates included in the analysis (all $P$ values $>0.05)$.

\section{Adenoma detection rate}

Of the 119 individuals who attended an appointment and were screened, 9 (7.6\%) had one or more adenomas detected, 6 of whom also met the clinical criteria for colonoscopy and subsequently underwent further examination. No patient was diagnosed with cancer.

\section{Discussion}

This trial was initiated to test the impact of a 12-month reminder compared with usual care in an RCT. It is the first study to subdivide nonparticipants in order to test the effect of longterm reminders on former nonresponders and former nonattenders independently. This study also examined the added benefit of including a bespoke, theory-based leaflet with the reminder by including a third parallel arm to the trial design.

The results of this RCT provide strong evidence to support the use of a 12-month reminder in the national BSS program and highlight an additional benefit of including a bespoke, theory-based leaflet among a group of adults who have previously received the full suite of information as part of the initial invitation (uptake was $0.2 \%, 10.4 \%$ and $15.2 \%$ in the control, TMR$\mathrm{SIB}$, and TMR-TBL groups, respectively).

At the current rate of attendance (43\%) [3], inclusion of a 12 -month reminder in the national BSS program would increase uptake by approximately $6-9$ percentage points (estimated by multiplying the proportion of adults not attending an initial appointment [0.57] by the proportion of adults attending in response to the 12-month reminder either with the SIB [0.10] or the TBL [0.15]), depending on which of the two leaflets were adopted. As uptake was consistent between men and women, as well as between tertiles of socioeconomic deprivation, it is unlikely that implementing a 12-month reminder with either leaflet would exacerbate existing inequalities in participation [3].

It is interesting to note that while uptake did not vary by sex, area, or area-level deprivation, it did vary by previous episode status, with former nonattenders being more likely to book 
and attend an appointment than former nonresponders (14.2\% vs. $8.0 \%$ ). One possible explanation for this difference is that former nonattenders, who perceive fewer barriers and more benefits to screening than nonresponders, are qualitatively similar to screened adults, but have difficulty translating their intentions into actions due to circumstantial aspects, such as poor health [31]. Previous research by Ferrer et al. has shown that participation in CRC screening is a behavioral process comprising several qualitatively distinct stages through which individuals move based on their readiness to be screened [39]. Each stage is strongly associated with a specific set of attitudes and beliefs toward the test, and it may be that the interventions used in our study were more effective at facilitating forwardstage transitions in former nonattenders by addressing issues that are specific to those who have already engaged with the program by making an appointment. It is also possible that it may simply be easier to facilitate forward-stage transitions in individuals who have previously responded to the initial invitation than in individuals who have not, and so the higher response in former nonattenders may have been observed for this reason. It is also important to note that, contrary to previous studies suggesting that nonattenders might never translate their intentions into actions [30], we found that the attendance rate for those confirming an appointment was actually higher (although not significantly higher) among former nonattenders than former nonresponders $(81.2 \%$ and $73.0 \%$, respectively).

Although this particular subgroup of nonparticipants does not comprise a substantial proportion of the population (we find that they only account for approximately $10 \%$ of individuals), they do represent a willing group who respond well to these interventions and as such should not be excluded.

We also found that women who made an appointment were less likely to attend screening than men who made an appointment ( $68.3 \%$ vs. $80.5 \%$ ), and this was consistent with previous research examining factors associated with non-attendance [31]. One possible explanation as to why women were less likely to attend a screening appointment than men who made an appointment is that women perceive more barriers to (flexible sigmoidoscopy) screening [40], which make it more difficult for them to attend [8].

It is possible that a telephonic reminder would have been more effective [19-21]. However, telephonic reminders are not considered cost-effective for CRC screening and as such are not recommended by the European Quality Assurance Guidelines for Colorectal Cancer Screening [41]. In addition, the screening center does not have access to patient telephone numbers (unless patients have provided a number, in which case they are available for responders and a telephone reminder for the appointment is given). Given this and the results of the present study, we would advocate the adoption of a 12month mailed reminder for nonparticipants by the national program prior to full population coverage in 2018 . From a clinical perspective, this intervention can be considered worthwhile, given that the ADR reported in our study (7.6\%) is comparable to the rate associated with the initial invitation (9.8\%) [24].
There has been little positive research concerning the impact of theory-based materials on CRC screening rates [1218], particularly with regard to flexible sigmoidoscopy screening [21]. The finding that the bespoke, theory-based leaflet used in this study was effective is therefore highly promising. Not only does it demonstrate that such materials can be effective, but also that they can be implemented in ways that do not contravene General Medical Council guidelines for informed consent. It is possible that this type of leaflet might also be effective at other stages of the invitation pathway (for instance, if sent with the pre-notification or pre-appointment reminder letters), although it may be that it worked well because it was sent to a group of individuals for whom the standard information was not suitable.

Our study has several limitations. First, we only tested the impact of a 12-month reminder at one screening center and cannot say whether the interventions described here would be as effective outside of the study setting. Furthermore, to ensure endoscopy capacity (i. e. that all appointments could be facilitated), we selected only a proportion of former nonparticipants for this trial and not the entire eligible population. At this point it would be important to investigate the feasibility of rolling out these reminders across the entire eligible population, as well as at other centers. Other factors, such as recent bowel symptoms [8], which are associated with uptake of BSS, could not be examined because our study was embedded within the program, which does not have access to this information. As such, it was not possible to obtain the frequency of people coming forward in response to the reminder for this reason. It would be informative to know whether those coming for the test in response to the reminder had experienced a recent bowel symptom and whether this played a role in their motivation for making an appointment when previously they had not attended. These individuals may be more likely to have bowel disease and thereby benefit from the test. Future studies using questionnaires alongside these reminders might be able to provide more information on this issue. Finally, as the reminder used in this study consisted of multiple components, including a choice of practitioner and options for the time and day of the appointment, it is not clear how much each component contributed to uptake. It would be prudent to evaluate each component independently and to investigate whether additional components, such as general practice endorsement, having the enema administered at the hospital, and offering a prebooked appointment, may augment the observed effect [41].

Consistent with previous studies, the present trial highlights that interventions which target nonresponders to take up screening after a missed appointment can be effective and enhanced in a number of ways [41]. The study is the first to show that sending a reminder to former nonattenders is also effective and that these individuals should receive such reminders alongside former nonresponders. Additional reminders, possibly delivered at 24, 36, and even 48 months might improve uptake even further $[27,28]$. As an extension of the present trial, we are currently investigating whether there is an added benefit to sending a second reminder 24 months after the initial invitation. 


\section{Conclusions}

Use of a 12-month reminder in a single center of the English BSS Programme was effective and improved uptake among former nonresponders and nonattenders. Inclusion of a theory-based leaflet added significantly to this strategy, improving uptake even further. It is important now to test this strategy across multiple centers and the wider population. If consistent with the current study, implementing a reminder would increase population coverage and concomitantly increase the number of CRCs prevented by the program.

\section{Acknowledgments}

We would like to dedicate this article to Professor Jane Wardle (1950-2015).

We acknowledge funding support from St Mark's Hospital, University College London (UCL), and Cancer Research UK. R.S.K has a doctoral studentship funded by St Mark's Hospital and UCL; L.M.M. is funded by a CRUK Project Grant (C27064/ A17326) Awarded to C.V.W. We thank St Mark's Hospital for supporting this project. In particular, we would like to acknowledge the contributions of Lorraine Gorman and Cherese Bennett, whose advice and support from initial conception to completion were invaluable to this study.

\section{Competing interests}

None

\section{References}

[1] Department of Health. NHS Bowel Cancer Screening Programme. Piloting of flexible sigmoidoscopy - Advice to the NHS bidding process. 2012: Available from https://www.gov.uk/government/uploads/ system/uploads/attachment_data/file/215205/dh_132468.pdf Accessed 29 May 2015

[2] Atkin WS, Edwards R, Kralj-Hans I et al. Once-only flexible sigmoidoscopy screening in prevention of colorectal cancer: a multicentre randomised controlled trial. Lancet 2010; 375: 1624-1633

[3] McGregor LM, Bonello B, Kerrison RS et al. Uptake of bowel scope (flexible sigmoidoscopy) screening in the English National Programme: the first 14 months. J Med Screen 2016; 23: 77 - 82

[4] Geurts S, Massat N, Duffy S. Likely effect of adding flexible sigmoidoscopy to the English NHS Bowel Cancer Screening Programme: impact on colorectal cancer cases and deaths. Br J Cancer 2015; 113: 142 149

[5] Senore C, Ederle A, DePretis G et al. Invitation strategies for colorectal cancer screening programmes: the impact of an advance notification letter. Preventive Med 2015; 73: 106-111

[6] Holme $\varnothing$, Løberg M, Kalager $M$ et al. Effect of flexible sigmoidoscopy screening on colorectal cancer incidence and mortality: a randomized clinical trial. JAMA 2014; 312: 606-615

[7] Vernon SW. Participation in colorectal cancer screening: a review. J Natl Cancer Institute 1997; 89: 1406-1422

[8] Sutton S, Wardle J, Taylor T et al. Predictors of attendance in the United Kingdom flexible sigmoidoscopy screening trial. J Med Screening 2000; 7: 99-104
[9] Jones RM, Woolf SH, Cunningham TD et al. The relative importance of patient-reported barriers to colorectal cancer screening. Am J Preventive Med 2010; 38: 5 , 499-507

[10] Kobayashi LC, Wardle J, von Wagner C. Limited health literacy is a barrier to colorectal cancer screening in England: evidence from the English Longitudinal Study of Ageing. Preventive Med 2014; 61: 100 105

[11] Olynyk JK, Aquilia S, Fletcher DR et al. Flexible sigmoidoscopy screening for colorectal cancer in average-risk subjects: a community-based pilot project. Med J Australia 1996; 165: $74-76$

[12] Hardcastle J, Farrands P, Balfour T et al. Controlled trial of faecal occult blood testing in the detection of colorectal cancer. Lancet 1983; 322: $1-4$

[13] Tilley BC, Vernon SW, Myers R et al. The Next Step Trial: impact of a worksite colorectal cancer screening promotion program. Preventive Med 1999; 28: 276-283

[14] Kelly RB, Shank JC. Adherence to screening flexible sigmoidoscopy in asymptomatic patients. Med Care 1992; 30: 1029-1042

[15] Nichols S, Koch E, Lallemand R et al. Randomised trial of compliance with screening for colorectal cancer. BMJ 1986; 293: 107-110

[16] Pye G, Christie M, Chamberlain J et al. A comparison of methods for increasing compliance within a general practitioner based screening project for colorectal cancer and the effect on practitioner workload. J Epidemiol Community Health 1988; 42: 66 - 71

[17] Wardle J, Williamson S, McCaffery K et al. Increasing attendance at colorectal cancer screening: testing the efficacy of a mailed, psychoeducational intervention in a community sample of older adults. Health Psychology 2003; 22: 99

[18] Wardle J, von Wagner C, Kralj-Hans I et al. Effects of evidence-based strategies to reduce the socioeconomic gradient of uptake in the English NHS Bowel Cancer Screening Programme (ASCEND): four cluster-randomised controlled trials. Lancet 2016; 387: 751 - 759

[19] Stone EG, Morton SC, Hulscher ME et al. Interventions that increase use of adult immunization and cancer screening services: a metaanalysis. Ann Internal Med 2002; 136: 641-651

[20] Power E, Miles A, von Wagner C et al. Uptake of colorectal cancer screening: system, provider and individual factors and strategies to improve participation. Future Oncol 2009; 5: 1371 - 1388

[21] Senore C, Inadomi J, Segnan N et al. Optimising colorectal cancer screening acceptance: a review. Gut 2015; 64: $1158-1177$

[22] Lewis CL, Brenner AT, Griffith JM et al. The uptake and effect of a mailed multi-modal colon cancer screening intervention: a pilot controlled trial. Implement Sci 2008; 3: 32

[23] Hewitson P, Ward A, Heneghan C et al. Primary care endorsement letter and a patient leaflet to improve participation in colorectal cancer screening: results of a factorial randomised trial. $\mathrm{Br}$ J Cancer 2011; 105: $475-480$

[24] Bevan R, Rubin G, Sofianopoulou E et al. Implementing a national flexible sigmoidoscopy screening program: results of the English early pilot. Endoscopy 2015; 47: 225-231

[25] Libby G, Bray J, Champion J et al. Pre-notification increases uptake of colorectal cancer screening in all demographic groups: a randomized controlled trial. J Med Screening 2011; 18: $24-29$

[26] Allgood PC, Maxwell A], Hudson S et al. A randomised trial of the effect of postal reminders on attendance for breast screening. $\mathrm{Br}$ J Cancer 2016; 114: 171 - 176

[27] Lo SH, Halloran S, Snowball J et al. Colorectal cancer screening uptake over three biennial invitation rounds in the English bowel cancer screening programme. Gut 2015; 64: 282 - 291

[28] Steele R, Kostourou I, McClements P et al. Effect of repeated invitations on uptake of colorectal cancer screening using faecal occult blood testing: analysis of prevalence and incidence screening. BM] 2010; 341: c5531 
[29] Pisera M, Kaminski MF, Kraszewska E et al. Reinvitation to screening colonoscopy: a randomized-controlled trial of reminding letter and invitation to educational meeting on attendance in nonresponders to initial invitation screening colonoscopy (REINVITE). Eur J Gastroenterol Hepatol 2016; 28: 538 - 542

[30] Kerrison RS, McGregor LM, Marshall S et al. Use of a 12 months' selfreferral reminder to facilitate uptake of bowel scope (flexible sigmoidoscopy) screening in previous non-responders: a London-based feasibility study. Br J Cancer 2016; 114: 751 - 758

[31] Power E, Van Jaarsveld CH, McCaffery K et al. Understanding intentions and action in colorectal cancer screening. Ann Behavioral Med 2008; 35: 285-294

[32] Halloran SP. Bowel cancer screening. Surgery (Oxford) 2009; 27 : $397-400$

[33] Babbie ER. The practice of social research. Belmont, CA: Wadsworth publishing company; 1998

[34] Kiviniemi MT, Bennett A, Zaiter M et al. Individual-level factors in colorectal cancer screening: a review of the literature on the relation of individual-level health behavior constructs and screening behavior. Psychooncology 2011; 20: 1023-1033

[35] Rosenstock IM. The health belief model and preventive health behavior. Health Educ Behav 1974; 2: 354 - 386
[36] Bandura A. Health promotion by social cognitive means. Health Educ Behav 2004; 31: $143-164$

[37] Ramirez A, Forbes L. Approach to developing information about NHS cancer screening programmes. King's Health Partners; 2012

[38] Department for Communities and Local Government. English indices of deprivation. 2010: Available from https://www.gov.uk/government/statistics/english-indices-of-deprivation-2010 Accessed: 10 July 2015

[39] Ferrer RA, Hall KL, Portnoy DB et al. Relationships among health perceptions vary depending on stage of readiness for colorectal cancer screening. Health Psychology 2011; 30: 525

[40] Wardle J, Miles A, Atkin W. Gender differences in utilization of colorectal cancer screening. J Med Screen 2005; 12: 20 -27

[41] von Karsa L, Patnick J, Segnan N et al. European guidelines for quality assurance in colorectal cancer screening and diagnosis: overview and introduction to the full supplement publication. Endoscopy 2013; 45: 51

[42] Hudson S, Brazil D, Teh W et al. Effectiveness of timed and non-timed second appointments in improving uptake in breast cancer screening. J Med Screen 2016; 23: 160 - 163 